\title{
A Rural Perspective on the Practice and Challenges of Community Participation in Post-Apartheid South Africa Insights from Rural Beaufort-west Municipality
}

\author{
Dr Gregory Davids and T.Prince \\ School of Government, University of the Western Cape, South Africa \\ Dr Msuthukazi Makiva *(Corresponding Author) \\ School of Government, University of the Western Cape, South Africa \\ Dr Omololu Fagbadebo \\ Department of Public Management and Economics, Durban University of Technology \\ Republic of South Africa
}

\begin{abstract}
Post-apartheid South African (SA) government devised legalized platforms for citizen participation to channel their voice towards public policy formulation, implementation, outcome, and its impact. Instead of using these platforms, dissatisfied communities with service delivery resort to social protests and unrest. Indeed, citizens' voice and participation in government decision-making through social protests, is among the critical elements to democracy and good governance. The study sought to investigate the practice and challenges there are, with regards to community participation at the local level within selected rural communities, in South Africa. The study relied on qualitative research methodology to gather primary data. Extant literature was consulted to collect secondary data so that the phenomenon is greatly understood. The results showed that community participation is practiced as a once-off event instead of being viewed as a process that is comprised of interrelated activities. The study concludes that effective community participation requires continual engagement across the entire policy planning, decision making, and implementation stages. Furthermore, as each public policy phase has its challenges, flexible strategies are required to facilitate community engagement and participation. This, for instance, will increase the degree of decision-making consensus, while by default reduce the level of community dissatisfaction with service delivery, which currently South Africa experiences, through social unrest.
\end{abstract}

Keywords: Community participation, Service delivery, social unrest, Public engagement, Participation, local government, rural communities.

DOI: $10.7176 /$ PPAR/11-3-06

Publication date: April $30^{\text {th }} 2021$

\section{Introduction and background}

In pre-1994 South Africa, citizens were constrained by apartheid laws to freely participate in policy formulation and implementation. The apartheid government deliberately suppressed the voices of citizens in policy decisions and service delivery. Post-apartheid South African government sought to redress this challenge through inclusive policies, strategies, and instruments that would ermit unmitigated public participation in the policy process. According to Williams (2006:97), community participation in the post-apartheid South Africa "has literally become synonymous with legitimate governance".

Section 195(e) of the Constitution of the Republic of South Africa (1996) states, as one of its principles of public administration, "People's needs must be responded to, and the public must be encouraged to participate in policy-making". This public participation posture became a major responsibility of local government administration. One of the objectives of local government in South Africa, as prescribed by Section 152 (1e) of the Constitution, is "to encourage the involvement of communities and community organizations in the matters of local government". Section 44 ( 3 d \& h) 2, of the Municipal Structures Act 1998, empowers the executive Committees of the Municipalities to "annually report on the involvement of communities and community organizations in the affairs of the municipality: and ensure that regard is given to public views and report on the effect of consultation on the decisions of the council".

Beyond this, Section 57 (1b) of the Constitution also mandates the National Assembly to "make rules and orders concerning its business, with due regard to representative and participatory democracy, accountability, transparency and public involvement". In addition, the National Assembly has the Constitutional mandate to "facilitate public involvement in the legislative and other processes of the Assembly and its Committees; and openly conduct its business, and hold its sittings, and those of its Committees, in public (Section 59 (1a\&b) Constitution of the Republic of South Africa 1996). Sections 71 and 72, and 116 and 118, of the Constitution, 
extend these responsibilities to the National Council of Provinces and the Provincial legislatures, respectively. These pieces of legislation are designed to give effect, in part, to the Preamble of the Constitution, which sought to "Lay the foundations for a democratic and open society in which government is based on the will of the people and every citizen is equally protected by law; Improve the quality of life of all citizens and free the potential of each person".

Nevertheless, the post-apartheid South Africa has continued to witness civil disobedience and unrest by community members who have been venting their frustrations against poor service delivery. Despite the requisite constitutional provisions that guarantee public participation, governments at all levels, have shown a lack of commitment to community participation in the policy process (Williams, 2006; Marais, Quayle, and Burns, 2017; Ehren, Peterson and Baxter, 2020; Hofstetter, Bolding and van Koppen, 2020). In the face of accountability challenges and poor service delivery, South African communities have become mere spectators in the decision-making process of government. This paper examines the practice and challenges of community participation in the government decision making process in selected South African rural areas.

\section{Research methods and instruments for data collection}

This is a qualitative research paper, using the case study methodology. The location of the study was Beaufort West Municipality, a rural municipality, comprising of five towns geographically separated by farms. The municipality is confronted with the triple challenge of unemployment, poverty, and inequality. The majority of people are state-dependent because of the lack of employment. The economy is predominantly agrarian, and the municipality is a major employee responsible for delivery of basic public services. The qualitative methodology provided an insider's perspective of the phenomenon being researched. The sample was selected using the purposive sampling method to ensure stakeholder inclusivity. The sample comprised the municipal council officials, namely the executive mayor, the deputy mayor, and the speaker. The municipal administration included the municipal manager and the manager of community services. The community sample was drawn, using random sampling method, from the seven Wards. The data collection method was a two-pronged approach. The political leadership and the management were interviewed individually to garnish their perspectives whilst the focus group was used to interview the community members. The questionnaire guide was used to facilitate the one-to-one interviews and focus groups. To ensure validity, reliability, and objectivity of the findings, primary and secondary sources were used during the data collection process. The triangulation method ensured the validity, reliability, and credibility of the data collected and the subsequent findings and recommendation made.

\section{Conceptualizing community participation}

Public participation discourse is littered with perspectives on the primacy of the decentralized and inclusive public policy process. Thus, participatory democracy is a process "to meet the needs of the voiceless in the society" (Daudu and Fagbadebo, 2019: 34). In other words, members of the public with different concerns would be availed of the platform to express their concerns to seek solutions to the identified problems. Thus, public participation "connotes citizens' involvement in the process of proffering solutions to problems or taking part in the decision-making process that has direct impacts on them" (Daudu and Fagbadebo, 2019: 236-237).

Public participation in the decision-making process allows citizens to be part of the formulation, implementation, and evaluation stages of public policy and programs. Citizens' opinions and views are critical to the successful implementation of policies in the public sector (Daudu and Fagbadebo, 2019). This is an indication that members of the public would "have access to evaluate existing policies and review the contents of the proposals in respect of a new policy or decision of the government before implementation" (Daudu and Fagbadebo, 2019: 237). Thus, community involvement in the policy process eases the complexity associated with public acceptance of government projects.

The understanding of community participation informs the subsequent process design to engage communities in the decision- making process. In this regard, Blanchet (2008) postulates that participation could either be passive or active. In the first instance, communities become part of an initiative that is imposed on them. In this regard, the community is bystanders, and their input is required to endorse a future project. The project identification, planning, and implementation in this regard would be done without their active involvement in the relevant processes.

In the second instance, the project originates within the community as a real need that must be attended to. In the latter situation, the project's legitimacy and community buy-in increase positively. This is because the community would adopt the project as their own and make concerted efforts to ensure the project's success. This is not necessarily the case when the project is superimposed on the community. The later outdated developmental philosophy of deciding for the people was a characteristic feature of the previous apartheid regime within South Africa.

Marshland with his definition supports Blanchet's perspective in his study of community participation in 
Tanzania that a common understanding of community participation is problematic (Marshland, 2006). In this regard, he presents two views on participation. The one perspective held by international development experts that view participation as empowering and aimed at involving the local population in decision-making. The other one is a local or Tanzanian perspective, which states that citizens are obliged to contribute their labor and resources in a community effort to build the nation. This definition could be seen as two sides of the same coin: on the one hand, it is expected from the community to contribute to the country's development (Marshland, 2006). In this regard, the assumption is that the community has the necessary skills and means to contribute to development. This is a major task for a community that is caught within and struggling to get out of the poverty trap.

The communities often find themselves in this situation because of a lack of appropriate skills and technical proficiency on how to improve their situation (Quick and Bryson, 2016). Involving the community in the projects increases the project legitimacy and decreases dependency on others for assistance. The onus, therefore, is on the community to take the responsibility, and the lead to change the situation through active participation in the process and acquiring knowledge.

Davidson and Cotte (1989) aver that community involvement is not confined to specific activities but is circumstantial. Opportunities for involvement could arise during the conceptualization, implementation, monitoring, and evaluation of projects. The problem with circumstantiality is that community participation is treated as "being by chance" rather than deliberate. The authors explain the benefits of community participation to include the following.

- Firstly, it allows a cost reduction through the utilization of local labor and expertise.

- Secondly, it potentially leads to the implementation of appropriate responses through participation in decision-making.

- Thirdly, scare resources are allocated to address needs as identified by the local community (Davidson and Cotte, 1989).

Based on the aforementioned, it could be deduced that community participation is necessary for successful policy formulation and implementation. Planning and implementation without community input could lead to resistance and ultimate failure of projects. Community participation, therefore, needs to take place during the planning, implementation, and review stage of public policy. Community participation cannot be seen as a onceoff event but rather a process that involves various phases planned for by the local government. Differences prevail regarding what community participation is, and these differences inform the actual engagement process. Community participation is dependent on the active participation of citizens in local government decisionmaking processes.

\section{Community participation in South Africa}

South Africa's socio-political history pre-1994 was characterized by oppression and violation of the human rights of the black majority. The basic democratic principle of good governance did not form part of the South African apartheid government policy lexicon, as far as it pertained to the black majority. During the apartheid era, public participation and the government's interphase with the black community was non-existent (Daudu and Fagbadebo 2019). The black majority opinions and socio-economic needs were not considered significant by the apartheid government. The voice of the black South Africans was suppressed, ignored, and not part of the decision-making practices of government.

The first democratic election in 1994 ushered in a new democratically elected government committed to a people-centered developmental approach (The White Paper on Local Government, 1998). The local government was assigned Constitutional responsibility and compelled to create formal spaces for community participation (Constitution of South Africa, 1996). Local government, being the closest sphere of government to the people, was deemed as the delivery arm of the state and assigned the constitutional responsibility of including the community in the decision-making processes. Thus, the South African Constitution recognizes the importance of public participation in the policy process and made provisions for the involvement of citizens in governmental activities at all levels.

There are policies of government formulated to give effect to the constitutional requirement at the local level. A key policy document, the White Paper on Local Government, (1998), provided an analysis of the status of local government and its ability to provide shape to the new democratic constitutionally enshrined mandate. The White Paper findings indicated that the apartheid local government system and structure inherited in 1994 was inappropriate as a vehicle to implement the new constitutional mandate. It underscored the key responsibility of local government to engage with and respond to the needs of the people and develop appropriate interventions to improve on their quality of life. Local government was subsequently restructured to give effect to the constitutional mandate to create platforms and structures to facilitate community participation in the decision-making processes (Municipal Structures Act of 1998).

The process of restructuring resulted in the establishment of a new local government system. The number of 
municipalities was reduced, and back-to-back municipalities established. Municipalities were subdivided into smaller governing areas known as the Wards. The Wards were the formal spaces created for localized community participation (Municipal Systems Act of 1998). The thinking at the time was that the newly reconfigured municipalities would facilitate the inclusion of the community in their decision-making process. It was anticipated that this would, in turn, improve the credibility of local decision-making, leading to efficient, effective, and economical service delivery, and improved quality of life of the ordinary person.

Contrary to the assumption that Constitutional and legislative changes, coupled with local government restructuring, would bring about a satisfied community, protest actions became the order of the day. The dissatisfied community members, according to Booysen (2007), reverted to the old tried and tested method of taking their grievances to the streets. The protest actions were aimed at drawing the policy maker's attention to their plights. This was an indication that the decision-makers were out of touch with the realities of the communities. The reason for being out of touch with the community's realities can be found in the lack of meaningful engagement with the community on matters that affect them. Conradie (2014), in agreement with this assertion, posits that the paramount principle of community consultation and participation in the decisionmaking of local government appeared to have been violated judging by the number of community protest actions the country has witnessed.

\section{Active Citizenry}

Emmett (2000) explains that active citizenship is a key factor for effective community participation. Community participation is premised on the assumption that there is a community, which could participate in the development project. In other words, the community must have the necessary capacity and skills to participate meaningfully, in development projects aimed at improving their situation. The challenge associated with this is the empowerment of the community to translate their problem into action.

The World Bank (2017) noted that active citizenship is required to incorporate local knowledge and preferences into the decision-making processes of governments, private providers, and donor agencies. When potential beneficiaries can make key decisions, participation becomes self-initiated because citizens are involved in both the design and execution of the projects. Local participation is a way to improve on poverty targeting, build social capital, and increase demand for good governance. The legitimacy of the decisions and project implementation also increases. In the main, this is because the community feels that it is their project that they have decided on and it is not parachuted on them. The inference is that projects get community buy-in only if citizens have been involved in its inception.

According to Fischer (2006), citizens' participation is the cornerstone of the democratic political process. Citizens are close to service delivery points and consequently best placed to provide feedback whether a service delivery strategy had met its objective or not. A bottom-up approach of citizen participation in the policy process becomes essential not only for corrective action but also to improve resource allocation. Insua, Kersten, Rios, and Grima (2008) state that participatory democracy broadens citizen involvement and contribution. This, in turn, leads to greater legitimacy and acceptance of public decisions, greater transparency, and efficiency in public expenditure, and greater citizen satisfaction.

Public participation holds certain benefits; and is a contributing factor for good governance. According to Islam and Haque (2015), local governance involves ordinary citizens taking ownership of their development and participating in local project planning. Good governance revolves around satisfying the needs of society. Including communities in the decision-making processes is not only a fundamental requirement for good governance but fundamental that the future recipients are part problem-solving process (Williams 2006). Community participation produces a few positive results such as the desired outcomes are produced, increased societal satisfaction, and improves the trust relationship with the state. Communities comprise a multiplicity of stakeholders with diverse needs. The approach for successful understanding in part is to possess an understanding of community complexities and nuances.

In South Africa, requisite legislative frameworks support the involvement of citizens in the decision-making process. However, local governments have neglected this constitutional mandate, to engage, effectively, with and institutionalizing community participation in the decision-making processes. Consequence upon this is the spate of dissatisfaction amongst the communities, with the attendant poor service protest actions. This brings to the fore the need to examine the practice and challenges that negate effective community participation in rural areas.

Stakeholder diversity and impact of community participation

Local politicians view the community as homogeneous and oblivious to the diverse nature of society. The diversity of the community itself poses a problem to find a consensus position. The resultant effect is that a decision- position is adopted reflecting the viewpoint of the most vocal or dominant group. Mohan and Stokke (2000:249) concur with Emmett that understanding the local diversity such as social inequalities and power 
relations is necessary to ensure effective participation. The community comprises various stakeholders each with their own specific needs. The interest groups usually become involved in the community meetings to promote their interest and not necessarily the interests of the community. Understanding this complexity is necessary and must be taken into consideration during the planning phase to ensure a more focused community participation process.

The relevance of recognizing and understanding the diverse composition of the community, according to Mafukidze and Hoosen (2009:393) is key for effective community participation. These scholars further infer that the different actors have their self-interest at heart and not necessarily the interest of the community at heart. The pursuance of stakeholder self-interest could result in the voice of the marginalized becoming lost and, according to Tapscott and Thompson (2013), a failed community participation exercise. Tapscott and Thompson (2013) are of the view that if the diverse interest groups are not managed effectively, it could result in a failed community participation exercise. Failed community participation, according to them, is when the voice of the poor is not heard and the voice of the elite and powerful dominates. The powerful could capture the community participation meeting and the needs of the marginalized could dissipate. The local government as the facilitator of community participation ought to keep this in mind when planning for community participation.

In this regard, Tapscott and Thompson (2013) draw attention to the community participation official's responsibility in ensuring the success of participation. According to these scholars, the officials should possess the necessary skills and competencies to manage the community participation process. In this regard, officials would be able to identify and manage the different actors and their divergent demands. It is important to note that public officials occupy key roles during the stages of the community participation process. To possess the necessary skills will activate better engagement and preparedness for any concern communities may raise. Tapscott and Thompson (2013) point out that in many instances, some of the officials responsible for community participation demonstrate a lack of necessary skills to engage the communities. For example, community participation meetings are often emotionally charged, and for this reason, it is paramount that officials undergo formal training.

Officials are placed under tremendous political pressure to produce results and community participation is viewed as a means to end rather than an end itself. The officials have their key performance areas and community participation in many instances is not an important performance area. The resultant effect is that community participation is seen as a necessary irritation and not necessarily to improve better decision-making and improve service delivery outcomes. Effective community participation, therefore, requires that the key performance areas of the senior management reflect community participation as a priority.

Tapscott and Thompson (2013) postulate that the officials are technocrats and not schooled in handling the dynamics of community participation. The officials, most of the time are outsiders and unfamiliar with the social and power dynamics of the community. The officials are passersby in the development of the community and do not necessarily have the community interest at heart. According to Nyalunga (2006), the officials view civil society as agents of destabilization rather than equal partners in development. If Nyalunga's (2006) assertion is correct, then it will inform the type of engagement and relationship with the community. The community is therefore not viewed as equal partners in development, but rather as a secondary partner. Community participation under such conditions would not result in consensus but rather confrontation and development projects would be stalled. In those instances, the approach is not consultation but top-down information sharing on intended programs. This approach is in line with the "means to an end" view of community participation, as expressed by Parfitt (2004).

Parfitt (2004) points out that the "means to an end or the end itself" concept is at the heart of the concept of participation. The difference in philosophical underpinning finds its way in the power relationships of participation. The power relationship between the community and the state could either be one of consensusseeking and empowerment or dirigisme. If the participation philosophy is based on the means to an end, then it implies the following, that the community would be informed about planned projects and the community would be mobilized around project goals. This approach is based on a paternalistic view of the community disregarding local knowledge. The means to an end approach is short-term in focus and the involvement of the community comes to an end on project completion (Oakley, 1995). On the other hand, 'participation as an end' empowers people to pursue their development activities and projects. The latter approach increases the local buy-in and the legitimacy of the service delivery outputs. The community forms part of the problem-solving process if such arises during the service delivery implementation process.

The literature study revealed that most of the discourse centers on aspects that contribute to effective participation but not on the entire process of participation. This article focuses on the entire participation and integrates the various aspects. The point of departure is that all the different aspects of participation as highlighted in the literature study collectively contribute to a successful participation process.

\section{Research findings and discussion}


The research showed that community participation within the rural area is seen as a once-off event or a necessary irritation rather than viewed as part of the entire public policy process stages. This philosophical underpinning informs and influences all the processes associated with community participation. In particular, the municipal administration did not plan for community participation but only reacted to instructions from the municipal council. This lack of planning has had negative multiplier effects on the entire community participation process. Planning was mostly confined to the securing of a venue and informing the community of the meeting to be held. Other activities to ensure a successful community participation outcome were not considered. Key aspects such as the community diversity or who should be invited to the community meeting did not form part of the planning process discussion.

The findings showed that the municipality usually extends an open invitation to all community members irrespective of the topic of discussion is of interest to them. This view was substantiated by government officials when probed to determine if special arrangements were made for disability and language differences. When their attention was drawn to the constitutional requirements that the municipality must make specific arrangements for people with disabilities, the response was that the municipality did take into consideration people with disability and special needs but due to a lack of resources the government was unable to respond appropriately. When probed further, it became clear that it was not so much about the lack of resources, but rather a lack of recognition of the community diversity at the planning phase. The municipal ignorance in understanding and considering the community diversity resulted in a one-dimensional approach to community engagement.

The preferred and only method of engagement was face-to-face community meetings. Virtual community meetings, using electronic medium, was non-existent. The municipality operates in a fast-moving knowledge age and increased access to electronic media but failed to explore this important community participation platform. The municipality acknowledged that a problem existed regarding the attendance of community meetings but failed to explore other modes of engagement. Ignoring community diversity had a multiplier effect in as far as the effectiveness of community participation is a concern.

The findings revealed that multiple languages are spoken in the various Wards. The municipality language of communication at the meetings was mostly Afrikaans and the other languages were ignored. This language problem is a contributing factor to the lack of participation. The rural municipality is a predominantly Afrikaansspeaking community. Over the years, a large percentage of isiXhosa-speaking people have become residents of the community. The municipality did not take into consideration the multiple language use and continually used Afrikaans as the medium of communication at the meetings. Citizens have complained that the language usage at the meetings was Afrikaans, thereby excluded the Xhosa speaking language people from participation. This is not necessarily a serious challenge, but it became a problem because there was no interpreter at the meeting. The result is that many community members complained that they felt excluded and marginalized during the meetings. The insensitivity on the part of the municipality to the language diversity among the Wards is a contributing factor to the dwindling numbers of attendees.

The lack of understanding of community diversity is evident in planning for meetings. Little time was spent on planning for citizen's engagement. Planning concerns mostly operational matters such as the venue, time, and date of the meetings. Activities such as setting the agenda, identification of the target audience, required officials to attend the meeting, did not form part of the community engagement planning lexicon. This stemmed from the lack of understanding of community diversity, and hence the organizers did not appreciate the importance of planning for community participation.

Community participation has not become part of the organizational culture of the municipality, and the lack of institutionalization has created confusion on the appropriate stakeholder that was responsible for this important constitutional mandate. When this question was posed on whose responsibility community participation is, the blame game started. The administration views community participation as the political leadership responsibility and not theirs. According to the administration, their role is implementation whereas political leadership is participation. This narrow perception on the part of the administration influences their attitude towards public participation, which at best could be described as a non-commitment. The prevailing attitude amongst administrative staff reflects an attitude of community participation for the sake of participation and not necessarily to solicit meaningful community inputs to design and implement appropriate programs that are demand driven. This mind-set resulted in the lack of annual planning for participation, but knee-jerk reactionary planning is the modus operandi. Planning for community participation takes place at the request of the political leaders and not as part of the municipal annual operational plans.

An indifferent approach towards community participation characterizes senior management involvement, which starts and finishes with being invited to the community meeting. If not invited, senior management would not attend any community meeting. They are merely spectators in the community participation process whereas they ought to be the frontrunners. The role of senior management is to give effect to the legislative requirements and design and implement systems to facilitate community participation. One such legislative prescript, the 
Municipal Systems Act, legislates that municipalities must structure their administration in such a way as to encourage community participation. This fundamental administrative requirement to reconfigure the administrative structure to facilitate community engagement had not been done. The resultant effect is that no specific department or unit or system for that matter had been created to deal specifically with community participation. The absence of such a dedicated community engagement unit resulted in the weakening of this important legislative responsibility of community participation.

The municipality established formal spaces, namely Ward structures as platforms for community engagement as required by the Municipal Structures Act of 1998. The Ward structure at face value seems to be operational but the findings painted a different picture. The important formal governance structures are dysfunctional, and this finding supports the work of (Smith and de Visser, 2008). The Ward Committees had been designed as a local governance structure to engage communities at the coal face and to improve the response time in addressing localize needs. This key structure of engagement is not working properly as envisaged. The Ward Committee needs to be representative and reflects the diverse needs of the Ward. Ward Committees had not been elected in four of the seven Wards. In those instances where the Ward Committee had been elected the selection criteria were informed by political affiliation rather than competence and diversity. The non-functioning of Ward Committees is a contributing factor to the municipality's failure to engage with the community, thereby increasing community dissatisfaction and civil unrest.

The findings showed a few shortcomings concerning the actual community meeting. Ward meetings are not properly organized, and no formal agenda set to guide the discussion. The lack of formal agenda results in a free for and any matter tabled. The outcome of this is that the community complaint about services, such as education, social services, and so forth, which is not the municipality's constitutional responsibility. If the meetings are planned, then it would be focused and avoid discussing non-municipal matters.

The community has lost trust in and questioned the relevance of the Ward Committee as a decision-making structure. It is their view that their complaints were rarely attended to and the meetings were waste of time. The community similarly indicated that Ward Committee meetings were not an interactive decision-making session but rather an information-sharing session.

Furthermore, meetings were held at times that are not suitable for the community. The Ward Committee meetings, if held, were during the week after working hours. The time did not suit the community and more appropriate times must be determined that is suitable for the community and not necessarily the Ward councilor. The meetings very seldom start on time and this is frustrating and unprofessional. In many instances the local Ward councilor that called the meeting usually arrived late. This according to the community is disrespectful and many are left never to attend again.

The community does not know where to direct their complaints in the period between Ward Committee meetings. According to them, no formal mechanism exists where they could direct their complaints between Ward Committee meetings. This finding relates to the fact that the Ward councilor does not have a permanent office assigned for consultation. The community is therefore in the dark as to how to contact the Ward councilor and where to lodge their complaints.

The findings suggest that the community held the view that the meetings were convened for compliance's sake and not necessarily to genuinely engaged with the community. This perception is fueled by the fact that after the Ward Committee meetings very seldom if any feedback is given to the community.

Administrative support and capacity are a matter of concern, and the administrators lack the skill set to take meaningful minutes to reflect the key points at the Ward meetings. In the process, many of the issues discussed at the meetings disappeared. At times, no minutes of meetings were kept. In these cases, it depended on the Ward councilor to decide what matters were discussed and what decisions were taken. The findings indicated that the municipal officials responsible for community participation did not have the ability and knowledge to facilitate effective community participation. The officials had no formal training, they only gained experience through trial and error. Therefore, placing an inexperienced official to manage community participation does more harm than good. This is a key contributor to community participation failure.

The community expressed the view that the officials did not treat the community equally. According to them, the officials treated the community based on their social and economic status. This resulted in a large percentage of the community members questioning the sincerity of intent on the part of the municipalities to engage and include them in the decision-making processes.

The municipality similarly failed to respond meaningfully in engaging the middle-income group. This group rarely attends Ward Committee meetings, and rather engaged the municipality through the media or the writing of letters. The municipality, on the other hand, is struggling to develop alternative strategies to meaningfully engage the middle-income group.

The community participation process starts and ends with the actual community meeting. Very little thought on part of the municipal officials is given to what happens after the community meeting. How the key Ward meeting decisions are presented at a municipal council meeting. Beaufort West municipality comprises 
seven Wards that are competing for municipal resources. The municipal council decides on the competing Ward request presented. The result is that not all the Wards request is being granted. This results in a disconnect between the community expectation and actual implementation. As indicated earlier implementation is dependent on the municipal council decision making although at the Ward meeting an impression was created that the Ward request will be implemented. Exacerbating the situation is that no feedback is given to the Ward residence of the council decision outcome. The reason for this is two-fold; either the Ward councilor is of the view that everybody is aware of the municipal council decision outcomes or the Ward councilor is reluctant to provide feedback because the council did not support the request of the Ward. This could result in the Ward councilor losing credibility because an expectation of delivery was created at the Ward meeting.

The municipal administration is responsible for the implementation of council decisions. It is during the administrative implementation process that the community if they had not been informed of the municipal council decision, become aware that the Ward request will not be implemented. What the community believed would take place as decided at the community meeting will not materialize. This results in disillusionment amongst the community and many instances lead to social dissent and upheaval. This could have been prevented if timeous feedback after the municipal council meeting had been given.

Lastly, the data showed that the municipality does not review its community participation process. This is the key final stage of the community participation process because by doing so lessons could be learned to improve the process. The data showed that community participation is viewed from a narrow perspective that concludes with the community meeting taking place. The rest of the phases to complete the process of community engagement are neglected to result in community distrust of the process.

\section{Recommendations and Conclusion}

The article investigated what the practice and challenges are about community participation in rural communities. Municipalities must inculcate an organizational culture to derive a common understanding that community participation is integral to the delivery success of the municipality. Placing the community at the center in its decision-making would ensure that service delivery outcomes meet the societal demands. Community participation must be institutionalized and become part of the annual planning of the municipality. Institutionalizing community participation will contribute to establishing an organizational culture of consulting and including the community in the decision -making processes of the municipality.

The municipality must view community participation as a process comprising of different stages, namely: the pre-meeting planning phase; the community consultative meeting; the municipal council decision making and feedback; the administrative implementation process, and lastly the review phase. Opportunities for community participation and feedback must be created at each of the stages.

Community participation cannot be relegated to a once-off community meeting but forms part of the entire process of planning and implementation. In addition, municipalities must realize that community participation begins with a request from the community that is filtered through a decision-making process and ends with the administration implementing the decision. If this understanding prevails, then the municipality must structure its administration in a manner that will facilitate the process. This will ensure that the community participates during the various phases of planning and implementation and enhances community buy-in and trust.

\section{Declaration of Conflicting Interest}

The author(s) declares no potential conflicts of interest concerning the research, authorship, and/or publication of the article.

\section{Funding}

The author(s) receive no financial support for the research, authorship, and /or publication of this article.

\section{REFERENCES}

Bingham, L., Nabatchi, T. and O'Leary, R. 2005. The New Governance: Practices and Processes for Stakeholder and Citizen Participation in the Work of Government. Public Administration Review. 65(5),

Blanchet, K. 2008. Participatory development: Between Hopes and Reality. International Social Science Journal. 53(170)

Booysen, S. 2007. With the ballot and the brick: the politics of attaining service delivery. Progress Development Studies 7,1.

Conradie, E. 2014. From Land Reform to Poo Protesting: Some Theological Reflections on the Ecological Repercussions of Economic Inequality. Scriptura 113(2014:1).1-16.

Daudu, I. A. and Fagbadebo, O. M. 2019. Public Participation in Legislative Oversight: A Review of Nature and Practice in Nigeria and South Africa. In O. Fagbadebo, F. Ruffin (eds.), Perspectives on the Legislature and the Prospects of Accountability in Nigeria and South Africa. Pp. 233-249 
Davidson, W. and Cotte, R. 1989. Sense of Community and Political Participation. Journal of Community Psychology. 17 (2),

Ehren, M., Peterson, A., and Baxter, J. 2020. Accountability and trust: Two sides of the same coin? Journal of Educational Change 21:183-213

Emmett, T. 2000. Beyond community participation? Alternative route to civil engagement and development in South Africa. Development Southern Africa 17(4),

Fisher, F. 2006. Participatory Governance as Deliberative Empowerment: The Cultural politics of Discursive Space. American Review of Public Administration. 36(1),19-40.

Hofstetter, M., Bolding, A. and van Koppen, B. 2020. Addressing failed water infrastructure delivery through increased accountability and end-user agency: The case of the Sekhukhune District, South Africa. Water Alternatives 13(3): 843-863

Insua, A., Kersten, G., Rios, J. and Grima, C. 2008. ToWards Decision Support for Participatory Democracy. Handbook on Decision Support Systems. Springer

Islam, F. and Haque, A. 2015. Importation of Good Governance at Local Self-government Institutions in Bangladesh. Journal of Public Administration and Governance. 15(4),

Mafukidize, J. and Hoosen, F. 2009. Housing Shortages in South Africa: A discussion of the after-effects of Community Participation in housing provision in Diepkloof. Urban forum. Springer

Marais, D. L., Quayle, M. and Burns, J. K. 2017. The role of Access to Information in Enabling Transparency and Public Participation in Governance A case study of Access to Policy Consultation Records in South Africa. African Journal of Public Affairs, 9 (6): 36-49.

Marsland, R. 2006. Community Participation the Tanzanian way; Conceptual Contiguity or power struggle. Oxford Development Studies 34(1),

Mohan, G. and Stokke, K. 2000. Participatory Development and empowerment; the dangers of localism. Third World Quarterly.

Murambo, T. June 2017. Beyond Public Participation: The disjuncture between South Africa environment impact assessment law and sustainable development. Potchefstroom

Electronic Law Journal 11(3):105

Nyalunga, D. 2006. An empowerment and robust civil society as an ideal strategic partner of a municipal manager in the promotion of community participation in local government. International NGO journal Vol1(3) December/November academic journals.org

Oakley, P.1995. Peoples participation in Development Projects. Intrac Occasional Papers Series 7, Intract, Oxford.

Parfit, T. 2004. The ambiguity of participation: a qualified defence of participatory development. Third World Quarterly, 25(3), 537-555.

Quick, K. S. and Bryson, J. M. 2016. Public participation. In Jacob Torbing and Chris Ansell (eds) Handbook in Theories of Governance. Cheltenham, and Northampton: EdWard Elgar Press.

Smith, T. 2008. The role of Ward Committees in enhancing participatory local governance and development in South Africa evidence from six Ward Committee case studies. University Western Cape Community Law centre.

Tapscott, C. and Thompson, L. 2013. Between supply and demand: the limits to participatory development in South Africa. International Review of Administrative Sciences. Vol 79(2) page(s): 368-385

The Republic of South Africa. Constitution of Republic of South Africa of 1996. Government Printers Cape Town

The Republic of South Africa. Municipal Structures Act of 1998. Government Printers Cape Town.

The Republic of South Africa. Municipal Systems Act of 1998. Government Printers Cape Town.

The Republic of South Africa. White paper on local government of 1998. Government Printers. Cape Town.

World Bank Group. 2017. Citizens as drivers of Change: How Citizens practice human rights to Engage with the State and Promote Transparency and Accountability. Washington. 